\title{
Research on Reasons for the Rapid Economic Growth of Japan After World War II*
}

\author{
Lele Zhang \\ Guangdong Ocean University \\ Zhanjiang, China
}

\begin{abstract}
After the Second World War, Japan's economy surpassed the West Germany in 1968 and became the third largest economic power after the United States and the Soviet Union after two stages of recovery and rapid growth. The main reason for Japan's rapid economic growth is still controversial for researchers of different countries. This article will analyze the reasons for Japan's rapid economic growth after World War II from the aspects of economy, political democratization, an open economic system, technological innovation, consumption revolution, and American support.
\end{abstract}

Keywords—world system; China; Japan; international relations

\section{INTRODUCTION}

After the Second World War, the GHQ led by the United States began to rule Japan for 6 years. The US policy toward Japan after World War II has generally undergone three stages of "complete suppression" (early postwar) - "support" (after the Cold War and the Korean War) - "suppression" (when Japan became an economic threat to the United States in the 1970s).

In the ever-changing world situation, how did Japan constantly change its economic strategy according to the situation at home and abroad and adopt corresponding measures to achieve economic recovery and prosperity and become the third largest economic power after the United States and the Soviet Union more than 20 years later has become an important topic for the study of the economic recovery of big countries. This article will analyze the reasons for Japan's rapid economic growth after World War II from the domestic and international factors.

\section{THE TWO STAGES OF JAPAN'S ECONOMIC DEVELOPMENT AFTER WORLD WAR II}

After the end of World War II, Japan has experienced two economic stages: the revival period (1945-1955) and the rapid growth period (1955-1973).

\section{A. The Revival Period (1945-1955)}

In the course of this project, the author has studied and analyzed the relevant historical documents of Japan's

*Fund project: the Doctoral Research Fund Project of Guangdong Ocean University, "Research on Post-war Japanese Foreign Policies" (Project No.: R18019). economic revival after World War II for nearly five years, especially the documents of Japan's economic history in the period of rapid growth. At the same time, the article carries out the research on this subject by using the relevant historical information from the Japanese official websites of the Ministry of Education, Culture, Sports, Science and Technology, Ministry of Foreign Affairs and other government departments of Japan as reference materials, and collecting and sorting out the relevant historical data from the magazines such as World and BungeiShunju. Based on the analysis of the important documents in Japanese history after World War II, some new ideas are put forward in the following.

First of all, the previous studies on the revival period are summarized as follows:

The study of occupation period includes Yugong Zhaoyi's Occupation and Reform (New Iwanami Book, 2008), focusing on the establishment of a new postwar Japanese constitution, demilitarization and democratization policies. The demilitarization policy includes the directives issued by GHQ with the United States as the core, the disarmament of Japan and the handling of war criminals. Regarding the democratization policy, Yugong Zhaoyi specifically analyzed and demonstrated the five reform directives of GHQ and the formulation of Japanese constitution. Yugong Zhaoyi maintained that the important reason why the five reforms of postwar GHQ could be carried out smoothly in Japan was the inheritance of Japanese society before and during the war, such as the "Full Scale Mobilization System" in wartime.

Xigu Qianbo and Saito's Washington System and JapanUS Relations (Tokyo University Publishing Committee, 1978) is an analysis of the historical changes in Japan-US relations after World War II from the formation and significance of Japan-US security system.

Magosaki Ukeru, in the Orthodoxy of Postwar History (Genesis Society, 2012), studied Japan's "pro-American line" after World War II from a critical standpoint. Especially after Japan's independence, Yoshida Shigeru continued to adhere to the unchanged complete criticism of the pro-American line. Magosaki Ukeru believes that on September 8, 1951, after the signing of the San Francisco Treaty, Japan gained independence and sovereignty, which is the greatest opportunity for Japan to realize its independent line. On the other hand, in his book Prime Minister Yoshida Shigeru, Kosaka Masataka praised Yoshida's diplomatic line with the 
United States very highly and regarded him as a "talent of prime minister, rare in a hundred years". The author and Magosaki Ukeru have different opinions on whether Japan was completely independent after the founding of the San Francisco Treaty. After the signing of the San Francisco Treaty, Japan was indeed independent. But I do not think at this time Japan has obtained "complete sovereignty". Since the signing of the San Francisco Treaty, the Japan-US Security Treaty and the Japan-US Status Agreement have also been signed, and according to the Japan-US Security Treaty and the Japan-US Status Agreement, the US military occupation of Japan or the status of Japan and the United States have not changed substantially. The author believes that under this historical background, the result of Japan's swift change of policy toward the United States can only be the suppression, exclusion and exile of the leaders by the United States. This is confirmed by the pursuit of the "independent line" of Mamoru Shigemitsu and its cabinet supporters.

The relevant research on the early occupation is of great importance to the study of Japan's rapid economic growth. The author believes that the revival period is the economic and political basis for the period of rapid growth. Politically, the "Japan-US security system" can also be said to be the basis of Japan-US relations after World War II. Through the formulation of a peaceful constitution, Japan has forever abandoned its right to war, and the Japanese government has begun a recovery strategy centered on economic growth. Economically, after the "land reform", the surplus rural labor force was completely liberated, and agricultural labor productivity was greatly improved, which provided a wealth of cheap labor for Japan's subsequent high-speed growth period. On the other hand, after the policy disintegration of many big chaebols, competition among enterprises has become fierce. It has become one of the reasons for Japanese enterprises to expand investment in equipment during the period of rapid growth. In addition, the Korean War in the revival period and the 180-degree change of US policy toward Japan and the subsequent support policy toward Japan due to the "special need of Korean" also played a great role in promoting Japan's rapid economic growth. Therefore, the author put the research on the revival period of Japan in the important position of postwar Japanese economic history.

\section{B. Rapid Growth Period (1955-1973)}

On the study of the period of high-speed growth, the author, first of all, analyzed and studied Takeda Qingren's High-speed Growth - Modern Japanese History Series (8) (Iwanami Shoten, 2008), Hashimoto Shoulang's Postwar Japanese Economy (Iwanami Shoten, 1995), the Compilation Committee of the History of International Trade and Industrial Policy's History of International Trade and Industrial Policy 1-5 (Economic Industry Institute, 1989), Hiroshi Yoshikawa's Rapid Growth 6000 Days to Change Japan (Yomiuri Shimbun Agency, 1997), Ezra F. Vogel's Japan First (1979), Postwar Japan's Economic Track - 50 Years of History of the Economic Planning Agency complied by Japan's Economic Planning Agency (Economic Planning Agency, 1997) and other dozens of reference books.

In his book High-speed Growth - Modern Japanese History Series (8) (Iwanami Shoten, 2008), Takeda studied and demonstrated the political and economic conditions of Japan from 1955 to 1974. Takeda's research results, methods of demonstration and the research perspective of Japanese history after World War II are very important reference materials for the study of postwar history. Takeda first analyzed Japan's political situation between 1955 and 1960 to illustrate the political basis for Japan's rapid economic growth. In addition, the reasons and process of Japan's rapid economic growth are discussed from the aspects of Japan's investment competition mechanism, technological innovation mode and open economic system (trade, foreign exchange liberalization) economically. Finally, the reasons for the end of Japan's rapid economic growth are discussed. Specifically it analyzed it from the strike of Nixon for two times and the two oil crises, and analyzed and demonstrated the problems of environmental damage, public hazards and over-thinning of rural population in the process of rapid growth.

In Japan as Number One, American sociologist Ezra Feivel Vogel analyzes the development of Japan's economy after World War II from the American point of view. In the book, Vogel spoke highly of Japan's rapid economic growth after the war in terms of knowledge learning, the role of the government, political structure, business management, education and welfare systems. Vogel explained the reason why Japan should be the mirror of the United States from the following aspects: "after World War II, Japan maintained a high economic growth rate, but its crime rate was extremely low", "the enthusiasm of Japanese learning is very high" and so on.

Hiroshi Yoshikawa, in his book Rapid Growth - 6000 Days to Change Japan, studies and discusses the changes of social features before and after the rapid economic growth of Japan after World War II. It mainly includes the changes of rural areas before and after the rapid economic growth, the changes of enrollment rate and employment rate, the direction of population movement, average life span, social operation mechanism and so on.

\section{REASONS FOR RAPID ECONOMIC GROWTH OF JAPAN}

\section{A. Previous Researches on Rapid Economic Growth of Japan}

The main reasons for Japan's economic revival after World War II are discussed in many works on postwar history. Takes Postwar Japan's Economic Track - 50 Years of History of the Economic Planning Agency (Economic Planning Agency, 1997), complied by Japan's Economic Planning Agency, as an example. Postwar Japan's Economic Track consists of two main parts. The first part focuses on the economic history of Japan from 1945 to 1973, discusses the role of the Economic Planning Agency, and analyzes and demonstrates the social changes caused by the rapid economic growth in Japan after World War II. In the part: The Secret of Rapid Growth, it explains the reasons for Japan's rapid economic growth after World War II from the role of the Economic Planning Agency, labor force, equipment investment, technological innovation, international trade and other aspects. The research and demonstration on this issue can be regarded as the most important part of postwar Japanese economic history research. 
The author also studied and sorted the relevant literature on the role of the Japanese government in the process of rapid growth. Take the Compilation Committee of the History of International Trade and Industrial Policy's History of International Trade and Industrial Policy (Economic Industry Institute, 1989) as an example. The book contains 17 volumes with very rich contents. In addition to the rich and complete record of historical facts, the analysis and evaluation of senior researchers are also included. Among them, the first volume and fifth volume of the general introduction analyze the impact of the industrial policies of the Ministry of International Trade and Industry of Japan on the rapid economic growth of Japan, and expound the contents, effects, historical background and functions of the trade and industry policies at that time in great detail. For example, in order to improve the international competitiveness of Japanese enterprises, the Ministry of International Trade and Industry has carried out the corresponding measures centered by rationalizing the industrial structure. Compared with other references in postwar Japanese history, History of International Trade and Industrial Policy is also very important to the study of this topic from the perspective of industrial structure that the book analyzes the economic running mode of Japan after the World War II. But it must be said that, like the Economic Planning Agency's Postwar Japan's Economic Track - 50 Years of History of the Economic Planning Agency, they have some exaggerated remarks about the role of the government in the process of the post-war Japanese economic revival. Therefore, the author has made an analysis of the relevant discussion and demonstration process, and has made a critical re-argument on them from the perspective of world system theory.

There are still great disputes in Japanese academia about the main reasons for the rapid economic growth of Japan after World War II. In Fundamental Reasons for Japan's Economic Leap after the Second World War (Japan's Economic News Agency, 50th Showa Year), Takahashi Kamekichi states that "the rapid growth is due to private enterprises, not to the Japanese government". Takahashi started from the industrial structure, and analyzed the development of heavy chemical industry and its important role in the process of economic revival in Japan. He believes that "the development of heavy chemical industry is revolutionary". At the same time, Takahashi also made a positive evaluation on the role of the Japanese government's fiscal policy, lifelong employment system, and the management strategy of Japanese enterprises. In Japan's academic circles, not a few researchers think the role of the Japanese government was the most important among main reasons for the post-war economic revival of Japan. In other words, they believe that it was precisely because of the effective fiscal policy, financial policy and economic plan of the Japanese government that Japan's economy recovered rapidly and grew rapidly after the war.

In order to carry out the research smoothly, the author referred to more than 200 articles in The World. The problems of occupation and democratization, the formulation of the new constitution, the cold war policy of the United States and the policy towards Japan, the deficit treasury bonds, the Korean War and Japan were studied in depth. By analyzing the relevant data of Japan's foreign exchange increase during the
Cold War and the Korean War, it is concluded that "special need of Korean is an important reason for Japan's economic revival after the Second World War". In addition, the author reproves the impact of the Vietnam War on the Japanese economy. The role of several unjust wars in promoting Japan's economic revival has hardly been discussed in Japanese academia.

At the same time, the author searched and analyzed a large number of data from the official websites of the Ministry of Education, Culture, Sports, Science and Technology, Ministry of Foreign Affairs, Japan History Association and other government and non-governmental organizations. The data and written materials published by Japanese Ministry of Education, Culture, Sports, Science and Technology and the Japanese Ministry of Foreign Affairs after World War II are of great significance to the study of postwar Japanese history. The author uses these data, charts and other materials in the argumentation, which can enable the reader to analyze the Japanese historical vicissitudes after World War II intuitively. It includes the white paper on the development of science and technology published by the Ministry of Education, Culture, Sports, Science and Technology, statistical data in various fields, publications and so on. Among them, there are energy supply data from 1960 to 1978 . According to that data, it can be inferred that petroleum ranked first in energy supply in Japan since 1962, and in 1960 one barrel of petroleum was only $\$ 1.59$. The analysis of these data is an important basis for studying the revival of Japanese economy after World War II. Through the analysis of the oil price under the international background at that time, it is concluded that the cheap and abundant oil supply provided the energy guarantee for the rapid economic growth of Japan. It has greatly improved the persuasiveness of this article.

\section{B. Domestic Reasons of Japan}

After repeated analysis and study of the above reference materials, the author outlined the basic outline of Japan's economic history after World War II. On this basis, taking the world system theory as the research methodology, this paper studies the Japanese economic history after World War II in a deeper level.

Firstly, summarize previous research and various opinions of Japanese researchers and analyze relevant data, and conclude the main reasons for Japan's economic revival after World War II in the following.

1) Democratization of economy and politics: Under the guidance of GHQ, the "land reform", "labor reform" and "disintegration of the chaebols" realized the democratization of the postwar Japanese economy. The formulation of the pacifist constitution has also enabled the democratization of politics to be realized. This is the social foundation for Japan's economic development after World War II.

2) An open economic system: Japan joined IMF in 1952 and joined GATT in 1955. Since then, Japan has realized the liberalization of trade and capital in stages. From the perspective of Japan's domestic labor productivity and the international competitiveness of commodities, this open 
economic system was very beneficial to the development of Japan's economy at that time.

3) Technology introduction and technological innovation: From 1955 to 1970, Japan introduced a total of 15,003 key technologies from other countries. At the same time, Japanese enterprises have made a lot of technological innovation. It is for this reason that Japan has rapidly realized the modernization of the industry.

4) Investment in equipment: Large-scale investment in civilian equipment, like the introduction of technology, has greatly promoted the modernization of Japan's manufacturing industry.

5) Capital accumulation: Huge capital accumulation is the source of Japan's economic growth. In particular, the inflow of savings from banks provided supplementary funds for the operation and investment of equipment of enterprises.

6) Consumption revolution: Through the expansion of personal consumption and government consumption expenditure, the domestic market of Japan has expanded rapidly. With the increase of enterprise profits, the income of laborers has also been increased rapidly. After the increase of income, the consumption has increased and the production of enterprises has been stimulated. Such a virtuous cycle is an important feature of the rapid growth of Japan's economy after World War II.

7) The role of the government: During the period of highspeed growth, the Japanese government promulgated policies of low interest rate, reducing corporate income tax, issuing treasury bonds, and implementing economic plans to promote economic growth.

\section{International Reasons}

1) U.S. support for Japan: U.S. support for Japan includes technology, living materials, military supplies, world bank loans and many other aspects.

2) Special needs of war: The Cold War and the Korean War were of great significance to the revival of Japanese economy after World War II. Politically, the US policy toward Japan has undergone fundamental changes. Militarily, Japan founded the police reserve force. Essentially, it is the resurrection of the army. Economically, Japan's industrial production was finally restored and surpassed the pre-World War II level on the basis of the special needs of the war as an important source of foreign exchange and industrial recovery.

3) Cheap and abundant oil supply: During the period of rapid growth, Japan imported a large amount of cheap oil from the Middle East, making it a cheap energy guarantee for the development of domestic industry. Of course, in the development model of long-term excessive dependence on foreign energy imports, the outbreak of the two oil crises also put a stop to the rapid growth of Japan's economy.

\section{JAPAN'S ECONOMIC REVIVAL UNDER THE WORLD SYSTEM}

\section{A. Disputes in Academic Circles and My Views}

As mentioned above, there is a great deal of controversy in the academic circles of Japan about the main reasons for Japan's economic revival after World War II.

On this issue, the author analyzes and studies the predecessor's research results at the same time, but also from different angles analyzes the post-war Japanese economic development process, and put forward some views. For example, analyzes the role of the Japanese government in high-speed economic growth. Many researchers have researched the role of financial policy and fiscal policy, but very few researchers researched the role of the government's economic plan. Some researchers hold negative views on the role of economic planning. By referring to History of Showa Economy (middle) (Japan Economic News Agency, Nikkei Library, 2012), co-authored by Haruhito Takeda, Jinsen Jiuxiong, Shinohara Miyohei, Zhongcun Longying, Yimoutian Chongmin, Xiangban Zhengnan, Zhuzhong Yixiong, Yuanlang and et al., we can see that they held an negative views on the role of the Japanese government at that time in the analysis of "the national income doubling plan", "widening income gap" and "price run-up" and other factors. In my opinion, the Japanese government's economic plan after World War II was not the main reason for the rapid economic growth of Japan at that time. In other words, even without these economic plans, the Japanese economy would certainly be successful. However, it is subjective that in the economic plan the Japanese government published a lot of survey and research data on the running direction of national economy and framework which were helpful for enterprises to grasp their development direction. That is, through the economic development plan, the Japanese government has defined the basic direction and goal of macroeconomic development. According to the economic plan formulated by the government, the economic departments of the government carried out various economic activities to raise and distribute funds, directly or indirectly assisting the development of Japanese private enterprises. As we all know, the macroeconomic regulation and control policy was one of the important means for the government to regulate the economic development. And its role is self-evident for Japan whose free market economy has not yet fully formed in the 1950s and 1960s. On the other hand, from an economic point of view, the inevitable problem with a country's sustained and rapid economic growth is "the price run-up". It is a process that the United States, Europe and China have all experienced, and it is determined by the basic law of economic development. The author also holds different views on the "widening income gap" from Japanese researchers. In my opinion, compared with other countries with fast economic growth in the world, Japan's income gap in the period of rapid growth does exist, but it should not be overstated. On the contrary, in the process of rapid economic growth after World War II, Japan has formed a national structure dominated by middle-income groups, which is also an important reason for Japan's "middle-class consciousness". 


\section{B. The Role of the United States in the Process of Japan's Economic Revival After World War II}

As for the role of the support from US to Japan after World War II, the mainstream views of Japanese academic circles and the view of the author are quite different. In Japanese academia, there are a lot of literatures about the rapid economic growth of Japan after World War II. But few of them regarded the US support as the main reason for the rapid economic growth of Japan. Most of them attributed the post-war economic revival of Japan to the efforts of Japanese government and Japanese enterprises and their people. The author believes that without the political, military support, scientific and technological export, life, military materials and financial support from the United States, it was impossible for the rapid growth of Japan's economy after the war. Of course, the U.S. government decides whether to promote Japan's economic prosperity on the basis of whether it is in line with the national interests of the United States. Just as in the early postwar period, the basic policy of the US toward Japan was about "demilitarization, democratization, treatment of war criminals", and carried out a harsh policy of repression against Japan. After the Cold War and the outbreak of Korea War, it turned to "give full support to Japan's economic recovery, political recovery, the revival of the police reserve" and let Japan become the front line of the United States against the Soviet Union. In the 1980s, when Japan became an economic threat to the United States, the United States immediately ended the rapid development of Japan's economy by means of "BIS regulation" and "foreign exchange manipulation". However, in view of the objectivity of historical development, in the period of high-speed economic growth of Japan, the United States' assistance on Japan's politics, economy, military and other fields is the most important international reason for its economic revival.

Based on the analysis of the previous research results and the author's research on the revival of Japan after World War II, the author attributes the revival of Japan's economy to economic and political democratization, an open economic system, technology introduction and technological innovation, equipment investment, capital savings, consumption revolution, labor force, the role of the government, the support from the United States, special needs of war and cheap and abundant oil supply.

In addition, after studying and analyzing the history of Japan's post-war economic revival, its reference function to China's economic development can be found out. First, in the gap issue between the rich and the poor, the formation of "middle-class consciousness" in postwar Japan, the reality of the social gap between the rich and the poor, especially the causes and solutions of the gap between the rich and the poor in the period of rapid growth, can be an important reference for China's current economic and social development. Second, in introduction and innovation of science and technology, we should not only actively introduce advanced achievements from developed countries, but also increase investment in independent research and development and innovation in key areas. Third, in terms of the balance of development, throughout the history of Japan's economic revival after World War II, we can see that Japan has made considerable progress in economy, but also produced serious environmental problems and pollution problems. As a lesson from history, we should speed up economic construction, but also attach importance to environmental protection and resource conservation. It is no longer possible for China to continue to exchange environmental damage for the primary mode of economic development. Forth, in the national education, Japanese government vigorously developed basic education after war, and Japanese enterprises invested a lot of money and time in training the skills of technical personnel. In addition, in terms of Japan's dependence on foreign capital, trade liberalization and other aspects, it also has important reference value for China to formulate various policies suitable for China's economic development.

\section{CONCLUSION}

While comparing the research results of predecessors, the article analyzed the history of Japan's economic revival under American occupation from the perspective of "hegemonic system theory". Especially, the article researched and verified the role of it in various historical stages of Japan after the war in the construction of the most favorable "hegemonic system" for the United States. By developing the theory of world system into several concrete operation models of world system and applying this mode to the study of the history of post-war Japanese revival, from the perspective of the relationship history of the development of economic development and the development of social welfare system under the world system, the article focused on the complementary and competitive relations of "A - central country", "B - quasi peripheral country" and "C - peripheral country" at different levels, relooked and researched the postwar economic history of Japan, and concluded that: the change of Japan's role, or the interaction of the three layers $\{[\mathrm{A}] \rightarrow(\times)[\mathrm{B}] \rightarrow \times[\mathrm{C}]\}$ of world economy and political structure was the main reason for the prosperity and decline of Japan's economy after World War II in the operation course of world system (especially in the course of the construction of the most advantageous hegemonic system and international relations by the United States after the Second World War).

\section{REFERENCES}

[1] Zhang Lele. An Introduction to International Relations under the World System. Beijing: China Social Sciences Press, 2017.

[2] Zhang Lele. Lessons from Rise and Fall. Beijing: China Social Sciences Press, 2017.

[3] Murata Kunio. Democracy Theory under the Hegemonic System. Tokyo: Tea Bookstore, 2005.

[4] Yugong Zhaoyi. Occupation and Reform. Tokyo: New Iwanami Book, 2008.

[5] Takada Qingren. High-speed Growth: Iwanami Shoten, 2008.

[6] Hashimoto Hisarang. Postwar Japanese Economy. Tokyo: Iwanami Shoten, 1995.

[7] Hiroshi Yoshikawa. Rapid Growth - 6000 Days to Change Japan. Tokyo: Yomiuri Shimbun Agency, 1997.

[8] Japan Economic Planning Agency. Japan's Postwar Economic Track. Tokyo: Economic Planning Agency, 1997. 